\title{
Immunological and parasitological parameters after treatment with dexamethasone in murine Schistosoma mansoni
}

\author{
Ibrahim RB Aly ${ }^{1 /+}$, Mohamed A Hendawy ${ }^{1}$, Eman Ali', Eman Hassan ${ }^{1}$, Mona MF Nosseir ${ }^{2}$ \\ ${ }^{1}$ Department of Parasitology ${ }^{2}$ Department of Pathology, Theodor Bilharz Research Institute, Giza, Egypt
}

\begin{abstract}
This work aimed to evaluate the effect of diphenyl dimethyl bicarboxylate (DDB) and dexamethasone alone and in combination with praziquantel on various parasitological, immunological and pathological parameters reflecting disease severity and morbidity in murine schistosomiasis. DDB and dexamethasone had no effect on worm burden but altered tissue egg distribution. This indicates that, under the schedule used, neither drug interfered with the development of adult worms or oviposition, but both can modulate liver pathology. Dexamethasone resulted in a greater reduction in granuloma size than did DDB. Dexamethasone-treated mice also showed lower levels of serum gamma interferon (IFN- $\gamma)$, interleukin-12 (IL-12) and IL-4, together with higher IL-10 levels, than infected untreated control animals. These data suggest that dexamethasone is a convenient and promising coadjuvant agent that results in decreased morbidity in murine schistosomiasis.
\end{abstract}

Key words: schistosomiasis - morbidity - cytokines - treatment

Schistosomiasis is a chronic and debilitating disease that remains one of the most prevalent parasitic infections in the tropics, with an estimated 650 million people at risk of infection and 200 million people in 74 countries actually infected (WHO 2002). It is encouraging that, over the last several years in Brazil, China and Egypt, significant progress in the control of schistosomiasis has been achieved. However, due to environmental changes linked to water resources development and to rapidly increasing sizes and movements of population, the disease has spread to previously non-endemic or low endemic areas (Engels et al. 2002).

The main cause of morbidity and mortality in human schistosomiasis is hepatic fibrosis that essentially involves portal spaces without severe lesions in the hepatic parenchyma. Management of schistosomiasis has focused primarily on treating and preventing the complications of portal hypertension. Unfortunately, no therapy has been proven to prevent the progressive hepatic fibrosis associated with granulomatous hypersensitivity to parasite eggs. A proportion of patients with chronic schistosomiasis retain hepatic fibrous scarring of the liver following antihelminthic treatment. This problem has led to the suggestion that addition of antifibrotic agents as an adjuvant to anti-schistosomal chemotherapy may be useful in the treatment of Schistosoma mansoni infection.

Praziquantel (PZQ) remains the only antibilharzial drug effective against the four main schistosomes pathogenic to man (Gönnert \& Andrews 1977, WHO 2002).

\footnotetext{
+ Corresponding author: ibrahimshalash@yahoo.com

Received 12 October 2009

Accepted 5 July 2010
}

Although PZQ has been reported to have minimal side effects, control of schistosomiasis using PZQ at a population level faces some problems. PZQ resistance has been recently induced in schistosomes by laboratory selection (Fallon \& Doenhoff 1994). Reduced cure rates and failure of treatment after PZQ have been reported in Senegalese, Kenyan and Egyptian patients (Ismail et al. 1999, Fallon et al. 2000, Gryseels et al. 2001).

Dimethyl-4,4'-dimethoxy-5,6,5',6'-dimethylene dioxybiphenyl-2,2'-dicarboxylate (DDB), a component derived from Shizandrae, is a curative agent that is used clinically in East Asia (e.g., China and Korea) for the treatment of hepatitis. DDB protects liver tissue against carbon tetrachloride, galactosamine, thioacetamide and prednisolone-induced injuries and enhances antibody production (Liu 1987, Salama et al. 2004). A long-term randomized controlled human study has shown DDB to substantially improve liver function in patients infected with the hepatitis B virus (Liu 1987). We have reported that the pharmacological effects of DDB include inhibition of NF-KB activation and of TNF $\beta$ (Salama et al. 2004). Previous studies of the effects of corticoids on murine schistosomiasis showed variable effects that depended on the type of corticoid administered, the dose and the schedule of treatment (Harrison \& Doenhoff 1983, Morrison et al. 1986, Hermeto et al. 1990). It was proposed that the decrease in worm burden that occurred following corticoid treatment was due to impairment of the initial phase of parasite penetration into host tissues (Hermeto et al. 1994). Dexamethasone also decreased the level of collagen synthesis and the levels of enzymes associated with collagen synthesis (Newman \& Cutroneo 1978, James et al. 1983).

This study aimed to explore the effects of DDB and dexamethasone alone and in combination with PZQ on several parasitological, immunological and pathological parameters in murine schistosomiasis. 


\section{SUBJECTS, MATERIALS AND METHODS}

Laboratory-bred male Swiss albino mice, each weighing 18-20 g, were used in this study. They were maintained in conditioned rooms at $21^{\circ} \mathrm{C}$ on sterile water ad libitum and balanced dry food containing $24 \%$ protein. Animal experiments were carried out according to internationally valid guidelines (Nessim et al. 2000) at the Schistosome Biological Supply Program Unit of Theodor Bilharz Research Institute (SBSP/TBRI, Giza, Egypt).

Cercariae - S. mansoni cercariae suspension $(5 \mathrm{~mL})$ was obtained from SBSP/TBRI and placed drop-by-drop on a glass plate; $0.1 \mathrm{~mL}$ cercariae were killed by the addition of one drop of $1 \%$ iodine. With the aid of a dissecting microscope, the number of cercariae in $0.1 \mathrm{~mL}$ of suspension was determined. Generally, five counts were made to determine the average number of cercariae in $0.1 \mathrm{~mL}$ of the suspension. Infection was performed by subcutaneous injection of $100 \mathrm{~S}$. mansoni cercariae into each mouse (Stirewalt \& Dorsey 1974).

\section{Drug regimen}

$P Z Q$ - Because of the insolubility of this drug in water, tablets $(600 \mathrm{mg})$ were ground into white powder and suspended in $13 \mathrm{~mL}$ of $2 \%$ cremophore-EL. The drug was freshly prepared and orally administered to mice using a stainless steel oral cannula. The dose given was $500 \mathrm{mg} / \mathrm{kg}$ body weight for two consecutive days.

$D D B$ - DDB was supplied by Dongkwang Pharmaceutical Co. and was orally administered to mice using a stainless steel oral cannula. The dose given was $25 \mathrm{mg} / \mathrm{kg}$ body weight three times per week until the end of the experiment.

Dexamethasone disodium phosphate - Decadron (Prodome, Brazil) was injected intramuscularly at $1 \mathrm{mg} / \mathrm{kg}$ body weight three times a week until the end of the experiment.

\section{Experimental design}

The mice were divided into seven groups, each composed of 10 mice, as follows: group 1: normal control mice; group 2: infected untreated control mice; group 3: infected DDB-treated mice, animals in this group were orally treated with $25 \mathrm{mg} / \mathrm{kg}$ DDB three times per week for eight weeks, beginning on the first day of infection; group 4: infected DDB and PZQ-treated mice, animals in this group were orally treated with $25 \mathrm{mg} / \mathrm{kg}$ DDB three times per week for eight weeks, beginning on the first day of infection, they also received $500 \mathrm{mg} / \mathrm{kg}$ body weight of PZQ on two consecutive days at six weeks post-infection; group 5: infected dexamethasone-treated mice, animals in this group were intramuscularly treated with $1 \mathrm{mg} / \mathrm{kg}$ dexamethasone three times per week for eight weeks beginning on the first day of infection; group 6: infected dexamethasone and PZQ-treated mice, animals in this group were intramuscularly treated with $1 \mathrm{mg} / \mathrm{kg}$ dexamethasone three times per week for eight weeks beginning on the first day of infection; they also received $500 \mathrm{mg} / \mathrm{kg}$ PZQ on two consecutive days at six weeks post-infection; group 7: infected PZQ-treated mice, animals in this group received $500 \mathrm{mg} / \mathrm{kg}$ PZQ orally on two consecutive days at six weeks post-infection. Mice of all experimental groups were sacrificed at eight weeks post-infection and were subjected to the following investigations.

\section{Parasitological parameters}

Worm burden - Hepatic and portomesenteric vessels were perfuzed to recover worms for subsequent counting (Duvall \& DeWitt 1967).

Tissue egg load - The number of ova/gm intestinal or hepatic tissue was determined after digestion overnight in 5\% KOH (Cheever 1968, Kamel et al. 1977).

Percentage egg developmental stages ("oogram pattern") - The percentage of eggs at various developmental stages was examined in three samples from each mouse and the mean number of eggs at each stage/animal was determined (Pellegrino et al. 1962).

\section{Immunological study}

Serum enzyme assessment - Animals of all groups were weighed and then killed and blood was collected. Serum was separated by centrifugation at 3,000 $g$ for 10 min and stored at $-20^{\circ} \mathrm{C}$ for the assay of alanine aminotransferase (ALT) (EC 2.6.1.2) (Reitman \& Frankel 1957), $\gamma$-glutamiltransferase (GGT) (EC 2.3.2.2) using a Boehringer reagent kit (Mannheim, Germany), alkaline phosphatase (AP) (EC 3.1.3.1) (Kind \& King 1954), total protein (Weichselbaum 1946) and albumin (Doumas et al. 1971).

Cytokine assay - Serum IFN- $\gamma$, interleukin-4 (IL-4), IL-10 and IL-12 levels were measured at eight weeks postinfection using a sandwich enzyme-linked immunosorbent assay technique with capture and detection antibodies according to the manufacturer's instructions (PharMingen, San Diego, CA, USA). Recombinant cytokines were used as standards. Briefly, plates (Nunc, Roskilde, Denmark) were coated with capture antibodies followed by $100 \mu \mathrm{L}$ of serum sample or recombinant cytokine. Following addition of the biotinylated detection antibody and streptavidin-AP conjugate, the reaction was developed with paranitrophenyl phosphate (Sigma). Absorbance at $405 \mathrm{~nm}$ was measured with a Benchmark reader (Bio-Rad Laboratories Inc, Hercules, CA, USA). Assays were performed in duplicate. The cytokine concentration was calculated from a regression curve prepared using Microplate Manager software (Bio-Rad).

Histopathological study - Liver specimens were fixed in $10 \%$ buffered formalin and embedded in paraffin blocks. The prepared 4- $\mu \mathrm{m}$-thick sections were examined by light microscopy using hematoxylin and eosin and Masson trichrome stains.

Measurement of mean granuloma diameter was performed at a microscopic magnification of $100 \mathrm{X}$ using an ocular micrometer. Only non-confluent, lobular granulomas containing eggs in their centers were measured (von Lichtenberg 1962).

Statistical analysis - The data are presented as mean \pm standard error of the mean. The means of the different groups were compared globally using the analysis of variance ANOVA. Data were considered significant if $p$ values were less than 0.05 . 

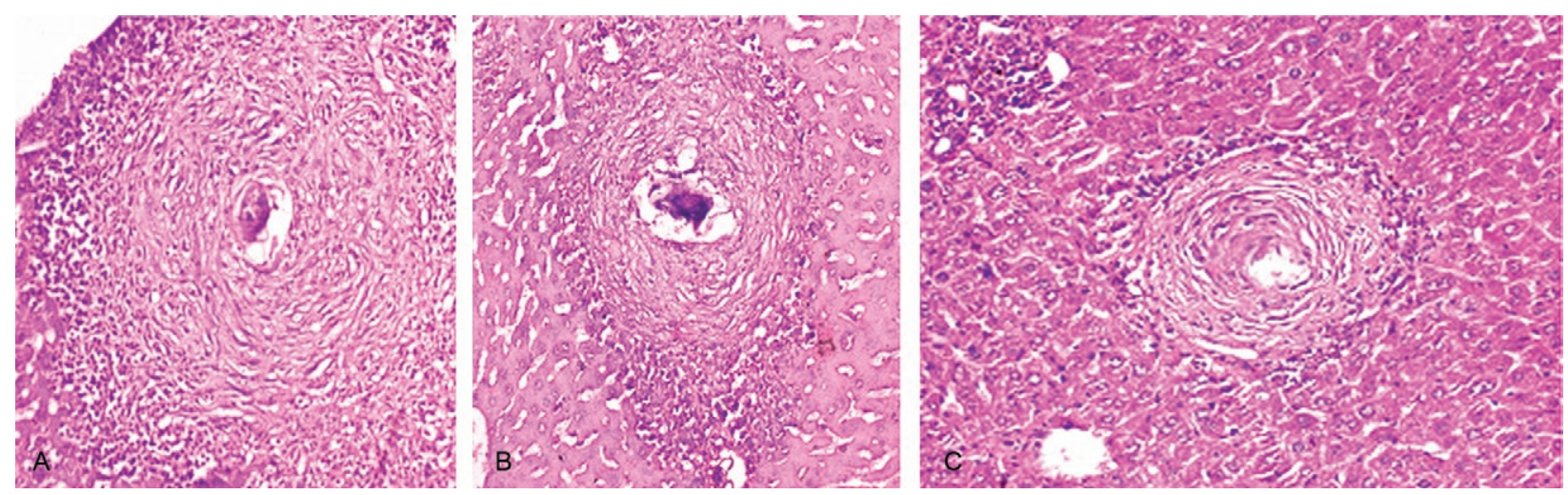

Effect of oral administration of dimethyl-4,4'-dimethoxy-5,6,5',6'-dimethylene dioxybiphenyl-2,2'-dicarboxylate (DDB) and intramuscular administration of dexamethasone on hepatic granuloma diameter of mice infected with Schistosoma mansoni. A: infected control; B: dexamethasone + praziquantel (PZQ); C: DDB + PZQ.

TABLE I

Effect of oral administration of DDB and intramuscular administration of dexamethasone on worm burden in different studied groups

\begin{tabular}{lcc}
\hline Animal group & $\begin{array}{c}\text { Mean number } \\
\text { of worms } \pm \text { SE }\end{array}$ & $\begin{array}{c}\text { Reduction on } \\
\text { worm burden } \\
\%\end{array}$ \\
\hline Infected control & $29.6 \pm 0.26$ & - \\
Dexamethasone & $25.6 \pm 0.31$ & 13.5 \\
Dexamethasone + PZQ & $1.6 \pm 0.35^{a}$ & 94.6 \\
DDB & $23.3 \pm 0.29^{a}$ & 21.3 \\
DDB + PZQ & $1.2 \pm 0.29^{a}$ & 95.9 \\
PZQ & $1.3 \pm 0.35^{a}$ & 95.6 \\
\hline
\end{tabular}

$a$ : statistically significant difference at $\mathrm{p}<0.001$ compared to infected control group; DDB: dimethyl-4,4'-dimethoxy5,6,5',6'-dimethylene dioxybiphenyl-2,2'-dicarboxylate; PZQ: praziquantel; SE: standard error.

\section{RESULTS}

The worm burden and tissue egg load in the intestine and liver were calculated for each studied group. In the infected control group, the total number of worms counted was $29.6 \pm 0.26$; these were divided between the liver (43\%) and the portomesenteric vein (57\%). Oral administration of DDB to infected mice reduced the total worm burden to $23.3 \pm 0.29$ (21.37\% reduction), whereas treatment of mice with dexamethasone alone reduced the total worm burden to $25.6 \pm 0.20$ (13.5\% reduction). Dexamethasone treatment was especially effective at reducing the number of worms in the liver (Table I). In contrast, administration of PZQ resulted in a marked $(95.6 \%)$ reduction in worm burden, with $60 \%$ of the worms shifted to the liver; inhibition was slightly increased when PZQ was given in combination with DDB (95.9\%). Following PZQ treatment, the oogram pattern showed complete disappearance of all immature ova from the wall of the intestine, a reduction in the number of mature ova and a four-fold increase in the number of dead ova. Treatment with dexamethasone alone significantly affected the number of dead ova and reduced the number of mature ova by 19 $20 \%$ while hardly affecting the number of immature ova. The combination of PZQ with DDB or dexamethasone augmented the effect of PZQ, resulting in $85 \%$ and $95 \%$ reductions, respectively, in the numbers of mature ova (Table II, III). Similar observations were made for egg load. PZQ reduced egg load both in the intestine (95.7\%) and in the liver $(96.4 \%)$ and its effect increased slightly upon combination with DDB. Treatment with DDB or dexamethasone alone also caused a decrease in egg load, to $76.8 \%$ and $72.7 \%$, respectively, in the intestine and to $76.1 \%$ and $66.5 \%$ in the liver.

Hepatic granuloma diameter was measured in each group. In the infected control group, the mean hepatic granuloma diameter was $318.8 \pm 26.3 \mu \mathrm{m}$. Oral administration of DDB decreased this value to $194.1 \mu \mathrm{m} \pm 21.2$ (39.1\% reduction) and administration of DDB in combination with PZQ decreased it to $168.1 \mu \mathrm{m} \pm 32.11$ (47.3\% reduction). Following intramuscular administration of dexamethasone, mean granuloma diameter decreased to $142.2 \mu \mathrm{m} \pm 25.1$ (55.4\% reduction) that reached $119.2 \mu \mathrm{m} \pm 29.5$ (62.6\% reduction) (Figure, Table IV). Thus, a significant reduction in granuloma diameter $(\mathrm{p}<0.001)$ relative to infected control was observed in both groups treated with dexamethasone.

Cytokine levels - Cytokines are believed to modulate fibrosis and granuloma size and to play a fundamental role in the pathology of schistosomal infection. To determine whether the modulatory effects of DDB and dexamethasone on granulomas are mediated through alterations in cytokine production, the levels of these mediators in serum were measured. Intramuscular administration of dexamethasone to infected mice induced significant decreases in the levels of IL-4, IFN- $\gamma$ and IL-12 compared to the levels of these cytokines in the untreated infected control group, whereas treatment of mice with DDB caused insignificant decreases in the levels of these cytokines (Table V). Significant increases in serum IL-10 levels occurred in the groups treated with DDB or dexamethasone. 
TABLE II

Effect of oral administration of DDB and intramuscular administration of dexamethasone on tissue egg load in different studied groups

\begin{tabular}{|c|c|c|c|c|}
\hline \multirow[b]{2}{*}{ Animal group } & \multicolumn{4}{|c|}{ Mean number of ova count $\pm \mathrm{SE}$} \\
\hline & Intestine & $\begin{array}{c}\text { Reduction } \\
\%\end{array}$ & Liver & $\begin{array}{c}\text { Reduction } \\
\%\end{array}$ \\
\hline Infected control & $14199 \pm 1342$ & - & $2877 \pm 411$ & - \\
\hline Dexamethasone & $3877 \pm 211^{a}$ & 72.7 & $965 \pm 255^{a}$ & 66.5 \\
\hline Dexamethasone + PZQ & $715 \pm 121^{a}$ & 95 & $178 \pm 40^{a}$ & 93.8 \\
\hline DDB & $3292 \pm 233^{a}$ & 76.8 & $689 \pm 98^{a}$ & 76.1 \\
\hline $\mathrm{DDB}+\mathrm{PZQ}$ & $545 \pm 133^{a}$ & 96.2 & $94 \pm 13^{a}$ & 96.7 \\
\hline PZQ & $612 \pm 156^{a}$ & 95.7 & $101 \pm 13^{a}$ & 96.4 \\
\hline
\end{tabular}

$a$ : statistically significant difference at $\mathrm{p}<0.001$ compared to infected control group; DDB: dimethyl-4,4'-dimethoxy-5,6,5',6'dimethylene dioxybiphenyl-2,2'-dicarboxylate; PZQ: praziquantel; SE: standard error.

TABLE III

Effect of oral administration of DDB and intramuscular administration of dexamethasone oogram pattern of mice infected with 80 Schistosoma mansoni cercariae and sacrificed eight weeks post-infection

\begin{tabular}{|c|c|c|c|}
\hline \multirow[b]{2}{*}{ Animal group } & \multicolumn{3}{|c|}{ Oogram pattern (\% ova) } \\
\hline & Immature & Mature & Dead \\
\hline Infected control & $65.3 \pm 5.4$ & $31.1 \pm 2.6$ & $3.6 \pm 0.7$ \\
\hline Dexamethasone & $50.2 \pm 4.2$ & $30.7 \pm 3.4$ & $19.1 \pm 1.5^{a}$ \\
\hline Dexamethasone + PZQ & $5.3 \pm 5.1^{c}$ & $4.3 \pm 1.4^{c}$ & $90.4 \pm 8.3^{c}$ \\
\hline DDB & $20.2 \pm 5.4^{b}$ & $43.2 \pm 6.1$ & $36.6 \pm 2.4^{b}$ \\
\hline $\mathrm{DDB}+\mathrm{PZQ}$ & $10.3 \pm 1.9^{c}$ & $6.5 \pm 1.4^{c}$ & $83.2 \pm 5.4^{c}$ \\
\hline PZQ & $2.3 \pm 0.4^{c}$ & $1.9 \pm 0.2^{c}$ & $95.8 \pm 4.9^{c}$ \\
\hline
\end{tabular}

$a$ : statistically significant difference at $\mathrm{p}<0.05$ compared to infected control group; $b$ : statistically significant difference at $\mathrm{p}<0.01$ compared to infected control group; $c$ : statistically significant difference at $\mathrm{p}<0.001$ compared to infected control group; DDB: dimethyl-4,4'-dimethoxy-5,6,5',6'-dimethylene dioxybiphenyl-2,2'-dicarboxylate; PZQ: praziquantel; SE: standard error.

Liver enzymes - Treatment of mice with DDB or dexamethasone reduced the levels of serum enzymes that reflect hepatic damage induced by infection, as shown by a decrease in the levels of serum ALT (78\% and $85 \%$, respectively), GGT (73\% and $86 \%$, respectively) and AP (76\% and $93 \%$, respectively). Treatment of mice with DDB or dexamethasone also tended to normalize the serum albumin level, which normally decreases following hepatic damage. Untreated infected mice showed a two-fold elevation in liver enzyme activity compared to normal control animals. Treatment of infected mice with PZQ alone reduced liver enzyme activity insignificantly. The highest significant reduction $(p<0.100)$ in liver enzymes was observed after treatment of infected mice with PZQ in combination with DDB or dexamethasone.

\section{DISCUSSION}

Schistosomiasis is a major public health problem in the tropics, with tens of millions of persons infected and many more at risk (Boros 1999). It has been estimated that more than 250,000 deaths per year are directly attributable to this disease (Botros et al. 2000) and the subtle morbidities associated with chronic schistosome infection have a serious impact. Treatment relies on a single drug, PZQ, to eliminate the adult worms; PZQ has no prophylactic properties and is ineffective against resistant strains (Botros et al. 2000).

Previous studies using non-steroidal anti-inflammatory drugs (NSAID) (e.g., tiaprofenic acid and piroxicam either alone or as adjuvant to PZQ) in treating hepatic granuloma in $S$. mansoni-infected mice have been reported (Hegazy et al. 1997). The possibility of using other NSAIDs, namely ibuprofen (CAS 15687-27-1) and naproxen (CAS 22204-53-1), either alone or in combination with PZQ (CAS 55268-74-1) has been suggested and has been shown to induce regression of hepatic morbidity and to ameliorate the biochemical and histopathological consequences and intensity of infection (Mahmoud et al. 2002). In the current study, we aimed to investigate the possible therapeutic effects of DDB and dexametha- 
sone administered alone and as coadjuvant therapy in the treatment of murine schistosomiasis.

Oral administration of DDB to $S$. mansoni-infected mice showed insignificant decrease in the worm burden and alteration of egg load in intestinal and liver tissue. However, administration of DDB in combination with PZQ decreased egg load in the intestine and in hepatic tissue by $96.2 \%$ and $96.7 \%$, respectively. Moreover, reduction in granuloma diameter and cytokine production indicated that administration of DDB to $S$. mansoni-infected mice may improve disease morbidity.

The protective effects of DDB on chemically-induced damage to isolated suspended rat hepatocytes were studied by Fu and Liu (1992) and its reversing effect on the phenotype of a human hepatocarcinoma cell line has

\section{TABLE IV}

Effect of oral administration of DDB and intramuscular administration of dexamethasone on hepatic granuloma diameter of mice infected with Schistosoma mansoni

\begin{tabular}{lcc}
\hline Animal group & Mean GD \pm SE & $\begin{array}{c}\text { Reduction } \\
\%\end{array}$ \\
\hline Infected control & $318.8 \pm 26.3$ & - \\
Dexamethasone & $142.2 \pm 25.1$ & $55.4 \%^{a}$ \\
Dexamethasone + PZQ & $119.2 \pm 29.5$ & $62.6 \%^{a}$ \\
DDB & $194.1 \pm 21.2$ & $39.1 \%^{b}$ \\
DDB + PZQ & $168.1 \pm 32.11$ & $47.3 \%^{b}$ \\
PZQ & $201.1 \pm 25.3$ & $24.1 \%^{b}$ \\
\hline
\end{tabular}

$a$ : statistically significant difference at $\mathrm{p}<0.001$ compared to infected control group; $b$ : statistically significant difference at $\mathrm{p}<0.01$ compared to infected control group; DDB: dimethyl-4,4'-dimethoxy-5,6,5',6'-dimethylene dioxybiphenyl-2,2'dicarboxylate; GD: granuloma diameter; PZQ: praziquantel; SE: standard error. been evaluated (Liu et al. 1996). Recently, administration of DDB to rats suffering from tamoxifen-induced liver injury revealed a potent anti-fibrogenic role of prolonged treatment (El-Beshbishy 2005). Moreover, a pharmaceutical composition of garlic oil and DDB as active ingredients for enzyme induction and liver protection has been used as a curative preparation for patients with acute or chronic viral hepatitis (Park et al. 2005). Dexamethasone has been previously investigated as a coadjuvant immunomodulator in treatment of chronic schistosomiasis (Pyrrho et al. 2002). In agreement with the results of Lambertucci et al. (1989), our results showed an insignificant effect of dexamethasone on parasite number. However, investigators who used hydrocortisone or a dose of dexamethasone 50 -fold higher than ours reported a decrease in the parasite burden (Coker 1957, Hermeto et al. 1993).

Following oviposition, schistosome eggs are carried mainly to intestinal and hepatic veins, then to the lungs and other tissues. A lack of $S$. mansoni fecundity following dexamethasone treatment in vitro has been described (Morrison et al. 1986) and a decrease in the amount of oviposition was reported after oral administration of dexamethasone in vivo (Lambertucci et al. 1989). Our results demonstrate that though neither worm development nor oviposition was significantly modified with the therapeutic schedule used, the treatment altered egg distribution in tissue, favoring a more intense deposition in the intestine.

The mechanism by which dexamethasone alters schistosome egg distribution in tissue is unknown. In addition, little is known about the effect of this glucocorticoid on the migration of female parasites and on the intravascular sites of oviposition. Following treatment of infected mice with corticosteroids or hydrocortisone acetate, a reduction in the rate of egg excretion with consequent changes in the places where the eggs are trapped in tissues was observed (Newsome 1963, Doenhoff et al. 1978). Because granulomas are composed of several cell types and extracellular matrix components, the action of dexamethasone on these elements is pleiotropic and dif-

\section{TABLE V}

Effect of oral administration of DDB or intramuscular injection of dexamethasone either alone or combined with PZQ on cytokine production of mice infected with 100 Schistosoma mansoni cercariae and sacrificed eight weeks post-infection

\begin{tabular}{|c|c|c|c|c|}
\hline Animal group & $\begin{array}{c}\mathrm{IL}-4 \mathrm{pg} / \mathrm{mL} \\
\mathrm{X} \pm \mathrm{SE}\end{array}$ & $\begin{array}{c}\text { IL-10 pg/mL } \\
\mathrm{X} \pm \mathrm{SE}\end{array}$ & $\begin{array}{c}\mathrm{IL}-12 \mathrm{pg} / \mathrm{mL} \\
\mathrm{X} \pm \mathrm{SE}\end{array}$ & $\begin{array}{c}\mathrm{IFN}-\gamma \mathrm{pg} / \mathrm{mL} \\
\mathrm{X} \pm \mathrm{SE}\end{array}$ \\
\hline Infected control & $770 \pm 160.1$ & $512 \pm 19.1$ & $150 \pm 10.1$ & $672 \pm 74.0$ \\
\hline DDB & $687 \pm 144.1$ & $612 \pm 46.5^{a}$ & $131 \pm 9.6$ & $607 \pm 63.0$ \\
\hline $\mathrm{DDB}+\mathrm{PZQ}$ & $712 \pm 155.2$ & $668 \pm 50.3$ & $138 \pm 12.5$ & $613 \pm 72.0$ \\
\hline Dexamethasone & $272 \pm 57.1^{b}$ & $711 \pm 23.1^{a}$ & $52 \pm 16.1^{b}$ & $127 \pm 54.0^{b}$ \\
\hline Dexamethasone + PZQ & $288 \pm 100.3$ & $698 \pm 33.0$ & $45 \pm 14.4$ & $192 \pm 94.0$ \\
\hline PZQ & $711 \pm 133.0$ & $588 \pm 45.5$ & $163 \pm 11.7$ & $633 \pm 53.0$ \\
\hline
\end{tabular}

$a$ : significant difference at $\mathrm{p}<0.01$ compared to infected control group; $b$ : significant difference at $\mathrm{p}<0.001$ compared to infected control group; DDB: dimethyl-4,4'-dimethoxy-5,6,5',6'-dimethylene dioxybiphenyl-2,2'-dicarboxylate; IL: interleukin; PZQ: praziquantel; SE: standard error; X: mean. 
ficult to evaluate in vivo. However, the mean granuloma size in animals treated with dexamethasone showed a significant decrease, probably due to the high levels of IL-10 induced by treatment. This observation is in accord with that of Franchimont et al. (1999), who showed that administration of exogenous IL-10 resulted in reduction of granuloma size. Furthermore, an opposite effect was seen in IL-10-deficient mice (Wynn et al. 1998). Rezende et al. (1997) suggested that immunocomplexes from patients with chronic intestinal schistosomiasis are able to modulate granulomatous hypersensitivity to $S$. mansoni eggs by inducing prostaglandin E production that augments IL-10 levels.

Cytokines are believed to modulate the amount of fibrosis and granuloma size and to play a fundamental role in the pathology of schistosome infection. To determine whether the modulatory effects of DDB and dexamethasone on granulomas are mediated through alterations in cytokine production, the levels of cytokines in serum were measured. Administration of exogenous IL-4 increases the amount of fibrosis (Yamashita \& Boros 1992), whereas administration of anti-IL-4 or exogenous IFN- $\gamma$ decreases the level of collagen deposition (Czaja et al. 1989, Cheever et al. 1994). In murine models, IL-12 was also involved in reduction of the amount of fibrosis and granuloma size (Wynn et al. 1995, Hoffmann et al. 1998). However, compared to wild-type mice, mice lacking IL-4 (IL-4 knockout mice) showed diminution in catalase levels and increased hepatotoxicity that resulted in early mortality (Fallon et al. 2000, La Flamme et al. 2001). In our study, administration of DDB or dexamethasone to $S$. mansoni-infected mice decreased serum IL-12 and IFN- $\gamma$ levels and markedly reduced IL-4 levels. However, it is possible that despite the observed decrease in IL-4 production, the circulating levels of this cytokine remain high enough to exert a protective effect. It has been suggested that IL-4 plays an important role in the severity of $S$. mansoni infection and may influence the course of disease (Brunet et al. 1998, Fallon et al. 2000). Because dexamethasone also increased serum IL10 levels, our data are in agreement with those from previous reports (Wynn et al. 1997, Hoffmann et al. 1999, 2000 ) and indicate that production of IL-10 is the key factor in preventing polarization towards a Th1 or Th2 profile and avoiding an increase in disease morbidity.

In conclusion, the use of DDB or dexamethasone as a coadjuvant treatment with PZQ in murine schistosomiasis may, in addition to minimizing the morbidity of infection, provide insight into the mechanisms involved in schistosomal pathogenesis.

\section{REFERENCES}

Boros DL 1999. T helper cell populations, cytokine dynamics and pathology of the schistosome egg granuloma. Microbes Infect 1: $511-516$.

Botros SS, Makary EA, Ahmed KM, Ibrahim AM, Nashed NN, ElNahal HM, Doughty BL, Hassanein HI 2000. Effect of combined praziquantel and recombinant glutathione S-transferase on resistance to reinfection in murine schistosomiasis mansoni. Int J Immunopharmacol 22: 979-988.

Brunet LR, Dunne DW, Pearce EJ 1998. Cytokine interaction and immune responses during Schistosoma mansoni infection. Parasitol Today 14: 422-427.
Cheever AW 1968. Conditions affecting the accuracy of potassium hydroxide digestion techniques for counting Schistosoma mansoni eggs in tissues. Bull WHO 39: 328-331.

Cheever AW, Williams ME, Wynn TA, Finkelman FD, Seder RA, Cox TM, Hieny S, Caspar P, Sher A 1994. Anti-IL-4 treatment of Schistosoma mansoni-infected mice inhibits development of T cells and non-B, non-T cells expressing Th2 cytokines while decreasing egg-induced hepatic fibrosis. J Immunol 153: 753-759.

Coker CM 1957. Effect of cortisone on natural immunity to Schistosoma mansoni in mice. Proc Soc Exp Biol Med 96: 1-3.

Czaja MJ, Weiner FR, Takahashi S, Giambrone MA, van der Meide PH, Schellekens H, Biempica L, Zern MA 1989. Gamma-interferon treatment inhibits collagen deposition in murine schistosomiasis. Hepatology 10: 795-800.

Doenhoff M, Musallam R, Bain J, McGregor A 1978. Studies on the host-parasite relationship in Schistosoma mansoni-infected mice: the immunological dependence of parasite egg excretion. Immunology 35: 771-778.

Doumas BT, Watson WA, Biggs HG 1971. Albumin standards and measurement of serum albumin with bromcresol green. Clin Chim Acta 31: 87-96.

Duvall RH, DeWitt WB 1967. An improved perfusion technique for recovering adult schistosomes from laboratory animals. $\mathrm{Am}$ J Trop Med Hyg 16: 483-486.

El-Beshbishy HA 2005. The effect of dimethyl dimethoxy biphenyl dicarboxylate (DDB) against tamoxifen-induced liver injury in rats: DDB use is curative or protective. J Biochem Mol Biol 38: 300-306.

Engels D, Chitsulo L, Montresor A, Savioli L 2002. The global epidemiological situation of schistosomiasis and new approaches to control and research. Acta Trop 82: 139-146.

Fallon PG, Doenhoff MJ 1994. Drug-resistant schistosomiasis: resistance to praziquantel and oxamniquine induced in Schistosoma mansoni in mice is drug specific. Am J Trop Med Hyg 51: 83-88.

Fallon PG, Richardson EJ, McKenzie GJ, McKenzie AN 2000. Schistosome infection of transgenic mice defines distinct and contrasting pathogenic roles for IL-4 and IL-13: IL-13 is a profibrotic agent. J Immunol 164: 2585-2591.

Franchimont D, Martens H, Hagelstein MT, Louis E, Dewe W, Chrousos GP, Belaiche J, Geenen V 1999. Tumor necrosis factor alphadecreases and interleukin-10 increases, the sensitivity of human monocytesto dexamethasone: potential regulation of the glucocorticoid receptor. J Clin Endocrinol Metab 84: 2834-2839.

Fu T, Liu G 1992. Protective effects of dimethyl-4,4'-dimethoxy-5, 6,5',6'-dimethylene dioxybiphenyl-2,2'-dicarboxylate on damages of isolated rat hepatocytes induced by carbon tetrachloride and D-galactosamine. Biomed Environ Sci 5: 185-194.

Gönnert R, Andrews P 1977. Praziquantel, a new board-spectrum antischistosomal agent. $Z$ Parsitenkd 52: 129-150.

Gryseels B, Mbaye A, De Vlas SJ, Stelma FF, Guissé F, Van Lieshout L, Faye D, Diop M, Ly A, Tchuem-Tchuenté LA, Engels D, Polman K 2001. Are poor responses to praziquantel for the treatment of Schistosoma mansoni infections in Senegal due to resistance? An overview of the evidence. Trop Med Int Health 6: 864-873.

Harrison RA, Doenhoff MJ 1983. Retarded development of Schistosoma mansoni in immunosuppressed mice. Parasitology 86: 429-438.

Hegazy IH, Nassar SH, Moussa SM 1997. Comparative effect of tiaprofenic acid and piroxicam alone and as adjuvants to praziquantel in Schistosoma mansoni infected mice. $J$ Egypt Soc Parasitol 27: 397-404. 
Hermeto MV, Bicalho RS, da Silva RE, de Melo AL, Pereira LH 1994. Oogram studies in mice infected with Schistosoma mansoni and treated with dexamethasone. Rev Inst Med Trop Sao Paulo 36: 99-104.

Hermeto MV, Bicalho RS, de Melo AL, Pereira LH 1990. Kinetics of the pulmonary phase of Schistosoma mansoni in mice treated with dexamethasone. Rev Inst Med Trop Sao Paulo 32: 168-171.

Hermeto MV, Melo AL, Bicalho RS, Vargas AP, Favaretto FJ, Pereira LH 1993. Dexamethasone does not reduce the worm burden in mice infected with in vivo obtained schistosomules of Schistosoma mansoni. Rev Inst Med Trop Sao Paulo 35: 389-390.

Hoffmann KF, Caspar P, Cheever AW, Wynn TA 1998. IFN-gamma, IL-12 and TNF-alpha are required to maintain reduced liver pathology in mice vaccinated with Schistosoma mansoni eggs and IL-12. J Immunol 161: 4201-4210.

Hoffmann KF, Cheever AW, Wynn TA 2000. IL-10 and the dangers of immune polarization: excessive type 1 and type 2 cytokine responses induce distinct forms of lethal immunopathology in murine schistosomiasis. J Immunol 164: 6406-6416.

Hoffmann KF, James SL, Cheever AW, Wynn TA 1999. Studies with double cytokine-deficient mice reveal that highly polarized Th1- and Th2-type cytokine and antibody responses contribute equally to vaccine-induced immunity to Schistosoma mansoni. J Immunol 163: 927-938.

Ismail M, Botros S, Metwally A, William S, Farghally A, Tao LF, Day TA, Bennett JL 1999. Resistance to praziquantel: direct evidence from Schistosoma mansoni isolated from Egyptian villagers. Am J Trop Med Hyg 60: 932-935.

James SP, Hoofnagle JH, Strober W, Jones EA 1983. NIH conference: primary biliary cirrhosis: a model autoimmune disease. Ann Intern Med 99: 500-512.

Kamel IA, Cheever AW, Elwi AM, Mosimann A 1977. Worm burden and tissue egg load in mice infected with PZQ-sensitive (CD) and -insensitive (EE10). Trop Med Hyg 26: 696-701.

Kind PRH, King EJ 1954. Determination of alkaline phosphatase activity in serum. $J$ Clin Path 7: 322.

La Flamme AC, Patton EA, Bauman B, Pearce EJ 2001. IL-4 plays a crucial role in regulating oxidative damage in the liver during schistosomiasis. J Immunol 166: 1903-1911.

Lambertucci JR, Modha J, Curtis R, Doenhoff M 1989. The association of steroids and schistosomicides in the treatment of experimental schistosomiasis. Trans R Soc Trop Med Hyg 83: 354-357.

Liu GT 1987. Clinical uses and pharmacology of DDB. A new drug for chronic viral hepatitis B. Proc CAMS and PUMC 2: 228-233.

Liu Z, Cui Q, Fu T 1996. Inducing effect of dimethy-4, 4'-dimethoxy-5, 6,5',6-dimethylenedioxybipheny-2, 2'-dicarboxylate (DDB) on differentiation of leukemia HL-60 cells. Zhonghua Yi Xue Za Zhi 76: $214-217$.

Mahmoud MR, El-Abhar HA, Saleh S 2002. The effect of Nigella sativa oil against the liver damage induced by Schistosoma mansoni infection in mice. J Ethnopharmacol 70: 1-11.

Morrison DD, Vande Waa EA, Bennett JL 1986. Effects of steroids and steroid synthesis inhibitors on fecundity of Schistosoma mansoni in vitro. J Chem Ecol 12: 1901-1908.

Nessim NG, Hassan SI, William S, el-Baz H 2000. Effect of the broad spectrum anthelmintic drug flubendazole upon Schistosoma mansoni experimentally infected mice. Arzneimittelforschung 50: $1129-1133$
Newman RA, Cutroneo KR 1978. Glucocorticoids selectively decrease the synthesis of hydroxylated collagen peptides. $\mathrm{Mol}$ Pharmacol 14: 185-198.

Newsome J 1963. Observations on corticosteroid treatment of schistosomiasis in hamsters and baboons. Trans R Soc Trop Med Hyg 57: 425-432.

Park EY, Ki SH, Ko MS, Kim CW, Lee MH, Lee YS, Kim SG 2005. Garlic oil and DDB, comprised in a pharmaceutical composition for the treatment of patients with viral hepatitis, prevents acute liver injuries potentiated by glutathione deficiency in rats. Chem Biol Interact 155: 82-96.

Pellegrino J, Oliveira CA, Faria J, Cunha AS 1962. New approach to the screening of drugs in experimental schistosomiasis mansoni in mice. Am J Trop Med Hyg 11: 201-215.

Pyrrho A dos S, Ramos JA, Neto RM, Silva CS, Lenzi HL, Takiya CM, Gattass CR 2002. Dexamethasone, a drug for attenuation of Schistosoma mansoni infection morbidity. Antimicrob Agents Chemother 46: 3490-3498.

Reitman S, Frankel SA 1957. Colorimetric method for the determination of serum glutamic oxalacetic and glutamic pyruvic transaminases. Amer J Clin Pathol 28: 56-63.

Rezende SA, Silva-Teixeira DN, Drummond SC, Goes AM 1997. IL-10 plays a role in the modulation of human granulomatous hypersensitivity against Schistosoma mansoni eggs induced by immune complexes. Scand J Immunol 46: 96-102.

Salama HM, Amer AR, Hammad OM, El-Sayed WF 2004. Effect of DDB monotherapy and in combination with amantadine hydrochloride and ribavirin in patients with chronic hepatitis $\mathrm{C}$ virus infection. Sci Med J ESCME 16: 128-134.

Stirewalt MA, Dorsey CH 1974. Schistosoma mansoni: cercarial penetration of host epidermis at the ultrastruetural level. Exp Parasit 35: 1-15.

von Lichtenberg 1962. Host response to eggs of S. mansoni. I. Granuloma formation in the unsensitized laboratory mouse. $\mathrm{Am}$ J Pathol 41: 711-731.

Weichselbaum TE 1946. Measurement of total protein in human serum. Amer J Clin Path Tech 16 (Suppl.): 40-49.

WHO - World Health Organization 2002. Prevention and control of schistosomiasis and soil-transmitted helminthiasis. World Health Organ Tech Rep Ser 912: 1-57.

Wynn TA, Cheever AW, Jankovic D, Poindexter RW, Caspar P, Lewis FA, Sher A 1995. An IL-12-based vaccination method for preventing fibrosis induced by schistosome infection. Nature 376: 594-596.

Wynn TA, Cheever AW, Williams ME, Hieny S, Caspar P, Kühn R, Müller W, Sher A 1998. IL-10 regulates liver pathology in acute murine schistosomiasis mansoni but is not required for immune down-modulation of chronic disease. J Immunol 160: 4473-4480.

Wynn TA, Morawetz R, Scharton-Kersten T, Hieny S, Morse HC 3rd, Kühn R, Müller W, Cheever AW, Sher A 1997. Analysis of granuloma formation in double cytokine-deficient mice reveals a central role for IL-10 in polarizing both T helper cell 1- and $\mathrm{T}$ helper cell 2-type cytokine responses in vivo. J Immunol 159: 5014-5023.

Yamashita T, Boros DL 1992. IL-4 influences IL-2 production and granulomatous inflammation in murine schistosomiasis mansoni. J Immunol 149: 3659-3664. 